ФИлология

DOI: $10.17805 /$ trudy.2017.5.10

\title{
«ОТЕЛЛО» СЕРГЕЯ ЮТКЕВИЧА В КОНТЕКСТЕ МИРОВОЙ КИНОШЕКСПИРИАНЫ"
}

\author{
Б. Н. Гайдин \\ Московский гуманитарный университет
}

Аннотация: Статья посвящена первой цветной экранизации «Отелло» У. Шекспира в мире - одноименного фильма режиссера С. И. Юткевича (1955). Автор предлагает свою версию того, почему работа советского режиссера не так часто попадает в поле исследований западных шекспироведов и киноведов в отличие от «Гамлета» и «Короля Лира» Г. М. Козинцева.

Статья подготовлена на основе доклада автора на круглом столе «Шекспир на советском экране» в рамках IX конференции Европейской шекспировской исследовательской ассоциации «Шекспир и европейские театральные культуры: (ан)атомизация текста и сцены» (Shakespeare and European Theatrical Cultures: AnAtomizing Text and Stage; 27-30 июля 2017 г., Гданьск, Польша).

Ключевые слова: С. И. Юткевич; «Отелло»; экранизации «Отелло»; У. Шекспир; шекспиросфера; Шекспир в современном кино; Шекспир в русской культуре; современный кинематограф; советское кино

\section{SERGEY YUTKEVICH'S “OTHELLO” IN THE CONTEXT OF THE WORLD FILM SHAKESPEAREANA}

\author{
B. N. Gaydin \\ Moscow University for the Humanities
}

Abstract: The article examines the first colourfilm version of W. Shakespeare's "Othello" in the world - the eponymous 1955 film directed by Sergei Yutkevich. The author proposes a possible reason why Western Shakespearean scholars and film experts have not paid much attention to the work of the Soviet director, compared to "Hamlet" and "King Lear" directed by Grigori Kozintsev.

The main points of the article were presented at the panel "Shakespeare on the Soviet Screen" at the 9th European Shakespeare Research Association Congress "Shakespeare and European Theatrical Cultures: AnAtomizing Text and Stage" (July 27-30, Gdańsk, Poland).

" Статья подготовлена в рамках проекта «Шекспир в современной русской культуре: национальное и глобальное», осуществляемого при поддержке Совета по грантам Президента РФ (MК-1182.2017.6). The article was prepared within the framework of the project "Shakespeare in Contemporary Russian Culture: The National and Global” with support from the Council for Grants of the President of Russian

Federation (MK-1182.2017.6). 
Keywords: Sergei Yutkevich; "Othello"; film adaptations of "Othello"; W. Shakespeare; Shakespearean sphere; Shakespeare in contemporary cinema; Shakespeare in Russian culture; contemporary cinematography; Soviet cinema

Как известно, единственный русский кинорежиссер, который вошел в плеяду режиссеров мировой киношекспирианы наряду с Л. Оливье, А. Куросавой и О. Уэллсом, - Г. М. Козинцев. Он, безусловно, был эрудированным исследователем, глубоким знатоком творчества Шекспира, что, конечно, во многом и помогло ему снять фильм «Гамлет» со И. М. Смоктуновским в главной роли на таком уровне, что картина стала классикой всемирного кинематографа.

Не очень широко известен факт, что одним из его друзей еще с юношеских лет в Киеве был другой советский режиссер, который также сильно интересовался Шекспиром и достаточно хорошо знал шекспировское наследие, а также историю его рецепции в мировом театре и кино, - Cергей Иосифович Юткевич, снявший в 1955 г. «Отелло» с С. Ф. Бондарчуком в роли мавра ${ }^{1}$.

«Отелло» С. И. Юткевича не приобрел широкой популярности в мире, да и в России этот фильм в настоящее время не столь известен, как «Гамлет» или «Король Лир» Г. М. Козинцева. Однако, по статистике интернетпроекта «КиноПоиск», в СССР фильм, вышедший на экраны 13 марта 1956 г., посмотрели 24,1 млн зрителей (Отелло (1955): Электронный ресурс). Это даже на 3 млн больше, чем у «Гамлета» Козинцева $-21,1$ млн зрителей (Гамлет (1964): Электронный ресурс). За «Отелло» Юткевич получил награду Каннского фестиваля 1956 года как лучший режиссер. Тем не менее, успех «Гамлета» Козинцева через 8 лет был куда больше, по крайней мере, на Западе.

С. И. Юткевич без всякого сомнения был талантливым кинохудожником со своим оригинальным режиссерским почерком. Ему принадлежит не малое количество статей, в которых он предлагает свое понимание различных пьес Шекспира и свое видение того, как можно экранизировать шекспировские произведения. В этой работе мы попробуем обозначить основные тезисы его видения содержания шекспировского «От-

\footnotetext{
${ }^{1}$ В одном из интервью сын Г. М. Козинцева, А. Г. Козинцев, отметил, что их тесная дружба продлилась до конца 1940-х гг.: «С Сергеем Иосифовичем отношения у отца были близкими до конца 40-х годов, в тяжелые минуты он писал именно ему. Потом произошло охлаждение - друга юности снова потянуло к Ленину тогда, когда отец уже сильно разочаровывался в идеалах молодости. Но “Баня” Юткевича - одна из ласточек кинооттепели - ему очень понравилась, как и “Сюжет для небольшого рассказа”». См.: Хазан, 2013: Электронный ресурс.
} 
елло» и попробовать оценить то, каким было влияние на него работ его предшественников («Отелло» Дмитрия Буховецкого / Dimitri Buchowetzki с Эмилем Яннингсом / Emil Jannings, 1922; «Отелло» Орсона Уэллса / Orson Welles, в котором режиссер сам сыграл роль мавра, 1952), а также попытаемся понять, можно ли говорить о том, что работа Юткевича оказала какое-нибудь влияние на более поздние экранизации «Отелло» (Стюарта Бёрджа / Stuart Burge с Лоренсом Оливье / Laurence Kerr Olivier, 1965; Оливера Паркера / Oliver Parker с Лоренсом Фишбёрном / Laurence Fishburne, 1995; Николаса Хайтнера / Nicholas Hytner с Адрианом Лестером / Adrian Lester, 2013).

В своей небольшой англоязычной статье «Мой путь с Шекспиром» (My Way with Shakespeare), опубликованной в журнале Films and Filming в октябре 1957 г., С. И. Юткевич писал, что уже нет сомнений, что пьесы Шекспира можно экранизировать, «главное теперь найти способ передачи содержания пьес на экране без огрубления, искажения, опошления или сведения их к тривиальности» (Yutkevich, 1957: 8; здесь и далее перевод наш. - Б. Г.). По его мнению, «все попытки представить лишь эффектные стороны его пьес, превращая их в костюмированную мелодраму или фантазию, как и все усилия использовать только “сюжет” пьес провалились» (ibid; курсив источника. - Б. Г.). Он считал, что сила шекспировских сочинений «не в сюжетных хитросплетениях, а в том, что он прибавлял к ним, в том цельном и могучем мировоззрении...» (Юткевич, 1973a: 194).

Идея экранизировать «Отелло» пришла режиссеру во время просмотра театральной постановки пьесы в одном из провинциальных театров (там же: 193). Секрет «эмоциональной привлекательности» этой шекспировской «трагедии любви и ревности» он видел в том, что в ней заключены «патетическая борьба за правду», «поиск и утрата безмятежного духа». Он считал, что «Отелло» не только «трагедия любви и мести», но и «трагедия веры, трагедия доверия и предательства» (Yutkevich, 1957: 8), кульминация которой происходит в тот момент, когда Отелло узнает, что его предал Яго.

С. И. Юткевич попытался сохранить последовательность сцен оригинала, не только динамику шекспировского текста, но и «все главные монологи... афоризмы и формы языка Шекспира, в которых заключены его основная красота и сила» (ibid). Режиссер позволил себе лишь в некоторых местах дополнить действие изображением природы, которая играет в произведениях Шекспира значимую роль. Это сложно показать в театре, тогда как кинематограф открывает больше возможностей. По мнению А. И. Высторобца, «пейзаж в фильмах С. Юткевича становится как бы соучастником происходящего. Его эмоциональность обусловлена драматургией и тесно связана с образной характеристикой персонажей и собы- 
тий» (Высторобец, 1981: 125). Далее киновед замечает, что «...в “Отелло” С. Юткевич и Е. Андриканис избегают эффектных, но искусственных построений. Цветовые композиции у Андриканиса предельно реалистичны. Насыщенность тона, обобщенность световых плоскостей помогают достичь выразительных цветовых сочетаний, не нарушающих этнографической точности и драматургической сущности используемого цвета» (там же).

Энтони Дэвис (Anthony Davies) также отметил значение природы в фильме: «Юткевич предлагает нам фильм с голубыми небесами, открытым морем и простором» ("Yutkevich gives us a film of blue skies, open sea and spaciousness”; Davies, 1994: 201). По мнению исследователя, в работе режиссера видна попытка «широкого использования мира природы в качестве драматического рефрена» (“the deployment of the natural world as a dramatic chorus”; ibid: 202). Юткевичу удалось показать «всеобъемлющую драматизацию природы» (“integrated dramatization of nature”), а также «ироническую связь между внешним и внутренним (психологическим) действием» ("ironic relationship between exterior and interior (psychological) action"; ibid).

До начала съемок актеры в течение шести недель репетировали, уделяя особое внимание кульминационным эпизодам. С. И. Юткевич не требовал у актеров сразу же играть «на пике» их возможностей, давал время вжиться в роль, вычленить в ней главное и второстепенное. По мнению режиссера, эта задача была несколько облегчена тем, что работа над сценами велась последовательно, т. е. в том же порядке, что и у Шекспира. Только финальная сцена, когда Отелло несет тело Дездемоны на башню, была снята раньше сцены убийства в спальне (Yutkevich, 1957: 8).

«Почти неразрешимая проблема», по словам режиссера, заключалась в том, что нужно было соединить поэтические реплики шекспировских героев с «реалистичной простотой» кино. Он хотел, чтобы фильм не носил отпечаток театральной условности, игра актеров не была бы слишком пафосной, но при этом не исчезла магия поэтического языка драматурга. С. И. Юткевич подчеркивал, что следует использовать все возможности кинематографа, чтобы создать «единство атмосферы и пламенных страстей трагедии», «некий образ в соответствии с идеями и стилем автора» (ibid). Он стремился «найти ритмический, музыкальный, ясный и яркий эквивалент потока шекспировских страстей» (ibid; курсив источника. Б. Г.). Режиссер считал, что нет какой-то необходимости что-то добавлять от себя, но обязательно следует показать то, что скрыто во фразах шекспировских героев, при этом не искажая оригинал (ibid).

«Тема трагедии» сопряжена у С. И. Юткевича с платком Дездемоны «символом доверия и любви», который затем превращается в «трагиче- 
ский знак неверности» (ibid: 32). Именно поэтому платок появляется в самом начале фильма и играет значительную роль в развитии его сюжета.

Следующей важной темой трагедии режиссер считал руки: черные руки Отелло на глобусе, игривые и заботливые руки Дездемоны, ее платок в руках Эмилии и т. д.

Использовал режиссер и возможности цветной пленки. Основные цвета: алый - цвет трагедии и беды (появляется в прологе и сопровождает Отелло, а в конце переходит на Дездемону и Эмилию), белый - цвет невинности (сопровождает Дездемону; по ходу действия он разбавляется розовым, а в конце - бледно-зеленым) и черный - цвет венецианского костюма Отелло, вечерних платьев Дездемоны, а также плаща Отелло в сцене клятвы. При этом задний фон создатели фильма стремились сделать нейтральным (спокойные тона серо-коричневого, переходящие в белый), чтобы эффект от костюмов главных героев был еще сильнее. Режиссер стремился использовать аутентичную архитектуру, чтобы декорации также играли важную роль в развитии действия и помогали актерам найти способы вызвать у зрителя новые чувства и ассоциации. Съемки велись в крепости XVI века, расположенной в устье Днестра, в городе Белгороде-Днестровском (Одесская область, Украина), а также на развалинах генуэзской крепости в Судаке (Крым) (Юткевич, 1973a: 215). Бюджет фильма не позволял соорудить величественную Лестницу гигантов, поэтому сцену сняли на речном вокзале в Химках (Московская область). Все сцены, происходящие в Венеции, были сняты в студии с использованием эффекта водяных бликов, поскольку не было возможности и средств искать венецианским каналам какую-то замену. Создатели фильма не гнались за достоверностью, в фильме присутствуют даже анахронизмы (например, фреска Учелло из Флоренции в сенате Венеции) (там же: 217).

Большое значение Юткевич уделял выбору ракурсов и движению камер (Yutkevich, 1957: 32). Использовался принцип «pars pro toto», т. е. «часть вместо целого»: «...ни одна массовка не превышала скромного количества пятидесяти человек, но прибавленные к ней в тройном или четверном количестве копья с флажками создавали праздничную многолюдную атмосферу приезда Отелло или ночного лагеря» (Юткевич, 1973a: 218). Сцену праздника снимали без участия многочисленной массовки: использовались имитация шума толпы, наложение музыки на кадры отснятых костров и фейерверков. Режиссер прибегал к приему выразительной мизансцены. Оператор Е. Н. Андриканис использовал возможности широкоугольного объектива «18» и соблюдал принцип, согласно которому камера двигалась только там, где необходимо, использовал паузы для акцентирования наиболее драматических моментов (там же: 220).

Музыку к фильму написал известный советский композитор А. И. Ха- 
чатурян, который, по словам С. И. Юткевича, построил свои сочинения по тем же принципам, что и он. Основные темы: «героическая тема Отелло, любовная тема Отелло и Дездемоны, темы платка, праздников, трагические темы отчаяния, песни солдат, ария Дездемоны, песня об иве и финальный реквием» (Yutkevich, 1957: 32). Кроме музыки в фильме широко использовались и возможности шумового оформления (пение цикад, тишина, шум волн, шепот моря и т. д.).

Почему же фильм не получил большого резонанса на Западе? Возможно, дело не только в том, что некачественно был выполнен англоязычный дубляж (Weiler, 1960: Электронный ресурс; Pregelj, 2011: Электронный peсурс), а качество афиш оставляло желать лучшего ${ }^{1}$. Можно предположить, что во многом фильм не привлек большого внимания, поскольку идеи, которые Юткевич так или иначе пытался передать в фильме, оказались во многом чужды и малопонятны иностранному зрителю.

Режиссер, как уже говорилось выше, придерживался коммунистических взглядов и старался следовать официальной линии соцреализма ${ }^{2}$. По крайней мере, сложно заподозрить его в какой-либо неблагонадежности или тайном диссидентстве, если прочитать его работы, так или иначе связанные с творчеством Шекспира. Ему удалось пережить сложное время репрессий, хотя и его работы, конечно, подвергались цензуре, а один фильм даже был запрещен ${ }^{3}$. Однако, как отметил киновед и историк кино П. А. Багров, Юткевич - «наверное, единственный в советском кино - реализовался до конца. Он сделал все, что хотел» (Багров, 2005: Электр. ресурс).

С. И. Юткевич подчеркивал, что «истолкование трагедии Шекспира становилось в руках буржуазных теоретиков активным орудием пропа-

${ }^{1}$ Выражаем благодарность Ронану Патерсону (Ronan Paterson) из Университета Тиссайд (Teesside University, Великобритания) за эту информацию.

${ }^{2}$ Интересно мнение П. А. Багрова о том, что С. И. Юткевич «на самом деле никак не мог вписаться в этот злосчастный соцреализм. Когда все причесывается под одну гребенку, противостоять этому может только художник страстный, художник, у которого есть “своя тема”. О чем бы ни делал кино такой художник, всегда эта тема пробьется наружу и произведет тем самым, быть может, даже более сильный эффект - как сейчас сказали бы, на “архетипическом” уровне. У Юткевича такой темы не было и быть не могло. А он, по природе своей, не мог не быть в авангарде - куда бы ни направляли этот авангард. Вот тут и начинается “общественно-политическая” карьера Сергея Юткевича: для многих она навсегда затмит его фильмы» (Багров, 2005: Электронный ресурс).

${ }^{3}$ Снятая им в 1947 г. на «Мосфильме» кинолента «Свет над Россией» по пьесе Н. Ф. Погодина «Кремлевские куранты» (1939-1 ред., 1956 - 4-я ред.) вызвала критику начальства за «неправильное» представление образа В. И. Ленина, а также за сцену свидания героев фильма в кафе поэтов, где звучит «Незнакомка» А. А. Блока. В итоге картина в прокат не вышла. 
ганды их идеологии; борьба велась вокруг Шекспира и за него» (Юткевич, 1973a: 194). Безусловно, и его «Отелло» во многом был отражением идеологической борьбы между западным и восточным блоками государств.

Он отмечал, что западные идеалисты видели в «Отелло» символическую борьбу добра и зла, высокого и низкого, пытаясь «утверждать через него извечность, неизменность, имманентность природы человеческих чувств» (там же). Он считал ошибочным мнение, что Шекспир сделал Отелло черным мавром для того, чтобы создать «контраст между его черным телом и светлой душой...» (там же: 195). Он решительно призывал отказаться от актерского штампа, при котором страстность героя объяснялась лишь его национальным характером. По его мнению, Шекспир специально сделал героя не только иноземцем, но и безродным, который добивается признания своими ратными подвигами. «Неверность» Дездемоны ввергает его мир в состояние хаоса: «Теперь навеки прощай, спокойный дух» (III, 3). Таким образом, «вся трагедия Отелло - это поиски и потеря этого спокойного духа, это огромная тоска и чаяние той гармонии человеческой личности, при которой только и возможна творческая, созидательная жизнь» (там же: 196). Но мечтает он, по мнению режиссеpa, не о счастливой жизни благополучного мещанина, а о судьбе солдата, «активного жизнестроителя» (там же).

С. И. Юткевич видел в Отелло «идеал гуманистов, о котором мечтал, к которому стремился Шекспир» (там же). Он считал, что любовь Дездемоны была для мавра «вершиной его жизненного пути... последним доказательством правоты его мироощущения» (там же). Ее утрата «означает для него крах его мировоззрения, конец его веры в высокое призвание и значение человека» (там же).

Режиссер ссылался на мнение переводчика и литературного критика И. А. Аксенова, который считал, что основным мотивом в творчестве Шекспира является поиск гармонии, создание человеком нового мира. Однако «его (Шекспира. - Б. Г.) идеалам не суждено было осуществиться, ибо грядущий новый мир - мир капитализма - был по-своему не менее дисгармоничен, чем феодальный мир» (Аксенов, 1937: 253-254).

В большинстве статей, посвященных «Отелло» С. И. Юткевича, с которыми нам удалось ознакомиться, отмечается оригинальность этой экранизации. Конечно, чаще всего работа Юткевича сравнивается с фильмом О. Уэллса. Советский режиссер сам написал несколько статей с критикой фильмов американского коллеги. Он отдавал должное мастерству Уэллса, который, как известно, часто вынужден был снимать свои работы в кратчайшие сроки из-за безденежья ${ }^{1}$. Режиссер указал, что единственным мо-

${ }^{1}$ Например, своего «Отелло» О. Уэллс снял всего за 21 день. Однако производство картины заняло три года: работа началась в 1949 г. и была представлена на Каннском 
ментом фильма, который роднит его фильм с версией Уэллса, является сцена бракосочетания Отелло и Дездемоны, которая отсутствует в пьесе Шекспира (Юткевич, 1973a: 212).

С. И. Юткевич отмечал, что ему была ближе игра Томмазо Сальвини, чем Эрнесто Росси (см, например: Луков, 2013: Электр. ресурс), поскольку он считал, что «Отелло» не столько трагедия о любви, ревности и мести, сколько «трагедия веры в человека, это трагедия доверия и предательства» (Юткевич, 1973a: 197). Таким образом, Отелло убивает Дездемону из-за того, что она, как его заставил думать Яго, убила в нем веру в человека. Когда же он узнает о предательстве и вероломстве близкого друга Яго, происходит кульминация его трагедии.

В заключение несколько слов о возможном влиянии предыдущих версий «Отелло» на работу С. И. Юткевича.

Киноверсию «Отелло» Дмитрия Буховецкого режиссер считал слабой. По его мнению, тот «поставил самого плохого “Отелло”, который совершенно не выдержал испытания временем» (Юткевич, 1973b: 12). Какихлибо подробностей Юткевич не приводит, однако из контекста следует, что он был убежден, что лучшие фильмы получаются у тех кинорежиссеров, у которых был значительный театральный опыт. Таким образом, нет оснований говорить о каком-то влиянии фильма Буховецкого на экранизацию Юткевича.

«Отелло» О. Уэллса, безусловно, оказал воздействие на советского режиссера: «...я пошел по следам Орсона Уэллса, для того чтобы раскрыть тайну его метода работы с актером» (Юткевич, 1973с: 100). Но во многом, «Отелло» Юткевича - своеобразные ответ Уэллсу. К примеру, он критиковал фильм Уэллса за чрезмерную напряженность и стремительность: «Действие в его “Отелло” разворачивается в столь стремительном темпе, что, даже зная текст Шекспира, вы с трудом улавливаете последовательность сюжетных ходов. Все напряжено, натянуто, как тетива у лука, монтаж лихорадочен - он увлекает, завораживает, временами захватывает, и в этом кроется его своеобразная сила, но вместе с тем и причина того разочарования, которое овладевает вами наряду со вздохом облегчения, когда оканчивается эта сумасшедшая гонка. Мне кажется, сила и слабость

фестивале 1952 года (см., например: Юткевич, 1973с: 91). Сам О. Уэллс вспоминал об этом так: «...картина снималась урывками. Мне три раза приходилось закрывать ее, ехать куда-то, зарабатывать деньги, потом возвращаться, а это означает, что в одном месте ты видишь меня глядящим куда-то за пределы кадра и в другом тоже - только вижу-то я уже другой континент, да еще и по прошествии года. В итоге, у картины появилось куда больше монтажных переходов, чем мне хотелось; сценарий был написан иначе, но мне приходилось прибегать к ним, потому что в моем распоряжении никогда не было всех актеров сразу» (Уэллс, 2011: 299-300). 
Уэллса заключены в том, что шекспировские фильмы при всей их бешеной динамике внутренне статичны. Режиссер не соблюдает законов ритмичного чередования моментов напряжения и пауз. Каждый свой фильм он сразу начинает с самой высокой точки и старается держать зрителя до конца на этом уровне. Но ведь это отнюдь не наиболее действенный способ овладения эмоциями публики. Осыпаемый градом непрерывных эмоциональных ударов, зритель как бы инстинктивно старается уходить от них, чтобы не быть “нокаутированным”, в результате многие из задуманных художником “аттракционов” повисают в пустоте, а автор, в свою очередь, выматывается в этой серии атак, как слишком азартный боксер, не продумавший тактику боя» (там же: 97).

Не отрицая права каждого режиссера на некоторые отступления от содержания пьесы Шекспира (например, образ Яго в клетке), Юткевич все же считал, что Уэллс чрезмерно вольно обращался с текстом: переставлял реплики и производил настолько многочисленные купюры (особенно сокращены были реплики Дездемоны и монологи Яго), «что от этого страдает поэтическая и философская основа пьесы» (там же: 99).

Наконец, по мнению Юткевича, в фильме воплотился «экзистенциалистский бунт», «трагедия отчуждения могучей, но обреченной личности» Уэллса - «белого негра» (там же: 105). Режиссер считал, что «уэллсовский Отелло действует на протяжении всего фильма не только как “незнакомец” в мире венецианской знати, но и как “белый негр”, вступивший в поединок со всем современным ему миром, который он отвергает и ненавидит, не в силах объяснить или изменить его» (там же: 106).

По мнению Э. Дэвиса, «фильм Юткевича существенно проще, чем (кинокартина. - Б. Г.) Уэллса. Там, где Уэллс склонен накладывать образы друг на друга и делать так, чтобы композиционный эффект сформировался в сознании зрителя, Юткевич стремится, возможно, сделать слишком много вопросов однозначными. Однако цвет в его фильме дарит нам несколько незабываемых образов, в которых природные элементы - камень, небо и море - действительно становятся многоголосием для драматического развития» (“...Yutkevich’s film is dramatically less complex than Welles's. Where Welles tends to juxtapose images and allow the composite effect to mature in the mind of the viewer, Yutkevich seeks, perhaps, to make too many issues explicit. However, the colour in his film presents us with some unforgettable images in which natural elements - stone, sky and sea - do become a chorus to the dramatic development"; Davies, 1994: 208).

Едва ли можно говорить о каком-то большом влиянии фильма С. И. Юткевича на более поздние экранизации «Отелло». Безусловно, при желании можно обнаружить некоторое сходство в отдельных эпизодах, но, на наш взгляд, вполне очевидно, что «картины мира» (см., например: Степин, 2001; Погорский, 2012, Кузнецова, 2015), показываемые режиссе96 
рами, совершенно разные.

К примеру, Патрисиа Тэтспо (Patricia Tatspaugh) считает, что фильмы О. Уэллса, С. И. Юткевича и О. Паркера «могут иметь схожие черты, но большая часть явных совпадений являются следствием общего источника и особенно наличия художественных образов Шекспира, а также того, что действие разворачивается в Венеции и на Кипре. Переплетаясь с другим образами фильма, очевидные заимствования предполагают своеобразие» (“...may share traits, but most of the apparent similarities stem from the common source and especially Shakespeare's imagery and the locations of Venice and Cyprus. Resonating with other images in the film, the apparent borrowings assume a singularity"; Tatspaugh, 2007: 150). Она же замечает, что в фильме «Отелло» О. Паркера также можно найти влияние и Уэллса, и Юткевича, но все же ему ближе реалистический подход Ф. Дзеффирелли. Паркер стремился к максимальному реализму, снимая фильм именно в Венеции и на Кипре, а также взял на роль главных героев более молодых актеров, следуя театральным тенденциям своего времени (см.: Ibid: 153-154).

Таким образом, если судить по работам западных киноведов и шекспироведов, то чаще всего «Отелло» С. И. Юткевича рассматривается как фильм, заслуживающий внимания лишь в некоторых аспектах (например, съемка природных стихий, использование возможностей цветной кинопленки, некоторые другие режиссерские находки). Основной режиссерский замысел и культурфилософское содержание картины практически не затрагиваются.

Интересно в этом отношении мнение Дэвида Гиллеспи (David Gillespie) о том, что «фильм выдержан в рамках стандартной советской практики обращения к шекспировским трагедиям, поскольку он заостряет внимание на социополитическом измерении конфликта. Таким образом, акцент с самого начала сделан на покорении и насилии, при этом венецианское общество изображено охваченным нетерпимостью и расизмом, ведущим феодальный образ жизни, который основан на примитивных страстях и интригах, алчности, взяточничестве и распущенности. Тем не менее, его тема чести, любви и красоты, уничтоженных безжалостным злом, имела ясный актуальный резонанс в первые послесталинские годы» (“...film follows standard Soviet practice in dealing with Shakespeare's tragedies as it highlights the socio-political dimension of the conflict. Thus, the emphasis is on conquest and violence from the outset, with Venetian society shown as beset by bigotry and racism, a feudal way of life based on primitive passions and intrigue, avarice, venality and debauchery. Still, its theme of honour, love and beauty destroyed by an implacable evil had a clear contemporary resonance in the immediate post-Stalin years"; Gillespie, 2005: 50).

Фильм «Отелло» С. И. Юткевича стал первой цветной экранизацией 
трагедии венецианского мавра в мире и без всяких сомнений заслуживает внимания как оригинальная авторская работа. Представляется, что в будущем небезынтересным будет более детально рассмотреть возможные примеры влияния работы Юткевича на более поздние киноверсии «Отелло», которые пока оказались незамеченными.

Тем не менее, с нашей точки зрения, можно сделать вывод, что советская экранизация «Отелло» оказалась во многом непонятной и чуждой иностранному зрителю, критикам и киноведам. На наш взгляд, во многом она является таковой и для большинства современных российских кинозрителей.

\section{СПИСОК ЛИТЕРАТУРЫ}

Аксенов, И. А. (1937) Шекспир : статьи. Ч. І. М. : Гослитиздат. 363, [2] с.

Багров, П. А. (2005) Советский денди. Сюжет для небольшого романа [Электронный ресурс] // Сеанс. № 21/22: Трудно быть богом. Февраль. URL: http://seance.ru/n/21-22/yubiley-sergey-yutkevich/yutkevich/ (дата обращения: 24.10.2017).

Высторобец, А. И. (1981) Евгений Андриканис. М. : Искусство. 248 с.

Гамлет (1964) [Электронный ресурс] // КиноПоиск. URL: https://www. kinopoisk.ru/film/44457/ (дата обращения: 24.10.2017).

Кузнецова, Т. Ф. (2015) Культурная картина мира как ядро тезауруса в концепции Владимира Андреевича Лукова [Электронный ресурс] // Информационный гуманитарный портал «Знание. Понимание. Умение». № 3. URL: http://www.zpu-journal.ru/e-zpu/2015/3/Kuznetsova_CulturalWorld-View/ (дата обращения: 24.10.2017).

Луков, Вл. А. (2013) Росси Эрнесто [Электронный ресурс] // Электронная энциклопедия «Мир Шекспира». URL: http://www.world-shake.ru/ru/ Encyclopaedia/4496.html (дата обращения: 24.10.2017).

Отелло (1955) [Электронный ресурс] // КиноПоиск. URL: https://www. kinopoisk.ru/film/42842/ (дата обращения: 24.10.2017).

Погорский, Э. К. (2012) Картина мира // Знание. Понимание. Умение. № 4. С. 322-323.

Степин, В. С. (2001) Картина мира // Философский словарь / под ред. И. Т. Фролова. 7-е изд., перераб. и доп. М. : Республика. 720 с. С. 234-235.

Уэллс, О. (2011) Знакомьтесь - Орсон Уэллс = This is Orson Welles $/$ O. Уллс, П. Богданович ; [пер. с англ. С. Б. Ильина]. M. : Rosebud Publishing ; Пост Модерн Текнолоджи. 496 с.

Хазан, Л. (2013) Сын кинорежиссера Григория Козинцева доктор исторических наук Александр Козинцев: «Многие сцены в картинах отца навеяны киевскими воспоминаниями. Через них проходит один и тот же образ - измученного, затравленного человека обступает глумящаяся тол- 
па, обливая его помоями...» / Л. Хазан (корр.), А. Г. Козинцев [Электронный ресурс] // Бульвар Гордона. 14 мая. № 20 (420). URL: http://bulvar.com. ua/gazeta/archive/s20_66118/8126.html (дата обращения: 24.10.2017).

Юткевич, С. И. (1973a) «Отелло», каким я его увидел // Юткевич С. И. Шекспир и кино. М. : Наука. 271 с. С. 193-222.

Юткевич, С. И. (1973b) Введение в тему // Юткевич С. И. Шекспир и кино. М. : Наука. 271 с. С. 5-13.

Юткевич, С. И. (1973c) От гражданина Кейна до сэра Джона Фальстафа, или краткая история величия и падения мистера Орсона Уэллса // Юткевич С. И. Шекспир и кино. М. : Наука. 271 с. С. 71-113.

Davies, A. (1994) Filming Othello // Shakespeare and the Moving Image: The Plays on Film and Television / ed. by A. Davies, S. Wells. Cambridge : Cambridge University Press. xii, 266 p. P. 196-210.

Gillespie, D. (2005) Adapting Foreign Classics: Kozintsev's Shakespeare // Russian and Soviet Film Adaptations of Literature, 1900-2001: Screening the Word / ed. by S. Hutchings, A. Vernitski. London ; New York : RoutledgeCurzon. 228 p. P. $75-88$.

Pregelj,Z.(2011) Sergei Yutkevich:Othello-Отелло(1955) [Электронный pecypc]// Russian Film. March 1. URL: http://russianfilm.blogspot.ru/2011/03/ sergei-yutkevich-otello-1955-17.html (дата обращения: 24.10.2017).

Tatspaugh P. The Tragedies of Love on Film // The Cambridge Companion to Shakespeare on Film / ed. by R. Jackson. 2nd edn. Cambridge : Cambridge University Press, 2007. xii, 349 p. P. 141-164.

Weiler, A. H. (1960) Screen: Russian Version of 'Othello': Shakespeare Adaptation Opens at the 55th St. English Voices Used for Showing Here [Электронный ресурс] // The New York Times. May 16. URL: http://nytimes.com/ movie/review?res=9A04E7DB153DE333A25755C1A9639C946191D6CF (дата обращения: 24.10.2017).

Yutkevich, S. (1957) My Way with Shakespeare // Films and Filming. Vol. 4. No. 1. P. 8, 32.

Дата поступления: 25.10.2017 2.

Гайдин Борис Николаевич - кандидат философских наук, начальник Научно-исследовательского отдела цифровых технологий Института фундаментальных и прикладных исследований Московского гуманитарного университета, член-корреспондент Международной академии наук (IAS, Инсбрук). Адрес: 111395, Россия, г. Москва, ул. Юности, 5, корп. 6. Тел.: +7 (499) 374-59-30. Эл. адрес: bngaydin@mosgu.ru 
Gaydin Boris Nikolaevich, Candidate of Philosophy, Head of the Research Department of Digital Technologies, Institute of Fundamental and Applied Studies, Moscow University for the Humanities; Associate Member, International Academy of Science (IAS, Innsbruck). Postal address: Bldg. 6, 5 Yunosti St., Moscow, Russian Federation, 111395. Tel.: +7 (499) 374-59-30. E-mail: bngaydin@mosgu.ru

\section{Для цитирования:}

Гайдин Б. Н. «Отелло» Сергея Юткевича в контексте мировой киношекспирианы [Электронный ресурс] // Научные труды Московского гуманитарного университета. 2017. № 6. URL: http://journals.mosgu.ru/trudy/article/view/626 (дата обращения: дд.мм. гг.). DOI: $10.17805 /$ trudy.2017.6.10 